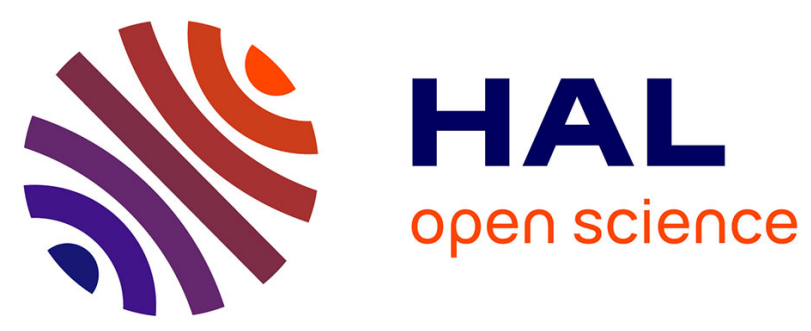

\title{
Comparative phylogeography among hydrothermal vent species along the East Pacific Rise reveals vicariant processes and population expansion in the South
}

Sophie Plouviez, T. M. Shank, Jean-Baptiste Faure, Claire Daguin-Thiébaut, Frédérique Viard, François Lallier, Didier Jollivet

\section{- To cite this version:}

Sophie Plouviez, T. M. Shank, Jean-Baptiste Faure, Claire Daguin-Thiébaut, Frédérique Viard, et al.. Comparative phylogeography among hydrothermal vent species along the East Pacific Rise reveals vicariant processes and population expansion in the South. Molecular Ecology, 2009, 18 (18), pp.39033917. 10.1111/j.1365-294X.2009.04325.x . hal-01218864

\section{HAL Id: hal-01218864 \\ https://hal.science/hal-01218864}

Submitted on 28 Jan 2016

HAL is a multi-disciplinary open access archive for the deposit and dissemination of scientific research documents, whether they are published or not. The documents may come from teaching and research institutions in France or abroad, or from public or private research centers.
L'archive ouverte pluridisciplinaire HAL, est destinée au dépôt et à la diffusion de documents scientifiques de niveau recherche, publiés ou non, émanant des établissements d'enseignement et de recherche français ou étrangers, des laboratoires publics ou privés. 


\section{Comparative phylogeography among hydrothermal vent species}

\section{2 along the East Pacific Rise reveals vicariant processes and}

\section{3 population expansion in the South}

4 S. PLOUVIEZ ${ }^{1,2, ~ *}$, T.M. SHANK ${ }^{3}$, B. FAURE ${ }^{4}$, C. DAGUIN-THIEBAUT ${ }^{1,2}$, F. VIARD $^{1,2}$,

5 F.H. LALLIER ${ }^{1,2}$ and D. JOLLIVET ${ }^{1,2}$

$6 \quad{ }^{1}$ Université Pierre et Marie Curie-Paris 6, Laboratoire Adaptation et Diversité en Milieu

7 Marin, Roscoff, France

$8 \quad{ }^{2}$ CNRS, UMR7144 Station Biologique de Roscoff, France

$9{ }^{3}$ Biology Department MS\#33, Woods Hole Oceanographic Institution, Woods Hole, MA

$10 \quad 02543$

$11{ }^{4}$ Department of Biology, Pennsylvania State University, University Park, Pennsylvania 12 16802, USA

15 Keywords: cytochrome oxidase I, deep-sea, Approximate Bayesian Computation, genetic

16 isolation, allopatry, past demography

17

*Corresponding author: Sophie Plouviez, Génétique de l'Adaptation en Milieux Extrêmes,

19 Station Biologique de Roscoff, Place Georges Teissier, BP 74, 29682 Roscoff cedex, France,

20 fax number, E-mail: plouviez@ sb-roscoff.fr

21

Running Title: Species vicariance on the East Pacific Rise 


\section{Abstract}

25 The use of sequence polymorphism from individual mitochondrial genes to infer past demography has recently proved controversial because of the recurrence of selective sweeps

27 acting over genes and the need for unlinked multi-locus datasets. However, comparative analyses using several species for one gene and/or multiple genes for one species can serve as a test for potential selective effects and clarify our understanding of historical demographic effects. This study compares nucleotide polymorphisms in mitochondrial Cytochrome

31 Oxidase I across seven deep-sea hydrothermal vent species that live along the volcanicallyactive East Pacific Rise. Approximate Bayesian Computation (ABC) method, developed to trace back shared vicariant events across species pairs, indicates the occurrence of two across-species divergence times, and suggests that the present geographic patterns of genetic differentiation may be explained by two periods of significant population isolation. The oldest period dates back 11.6 Mya, and is associated with the vent limpet Lepetodrilus elevatus, while the most recent period of isolation is $1.3 \mathrm{Mya}$, apparently affected all other species examined and coincides with a transition zone across the equator. Moreover, significant negative Tajima's D and star-like networks were observed for all southern

40 lineages, suggesting that these lineages experienced a concomitant demographic and geographic expansion about 100,000 to 300,000 generations ago. This expansion may have initiated from a wave of range expansions during the secondary colonization of new sites

43 along the Southern East Pacific Rise (founder effects below the equator) or recurrent

44 bottleneck events due to the increase of eruptive phases associated with the higher spreading rates of the ridge in this region. 


\section{Introduction}

Patterns of genetic variation are powerful tools for elucidating population history over time and space. The extent to which current genetic signals reveal past demography mostly depends on the mutational model of the molecular marker used (e.g., microsatellites, introns or exons) and the analytical methods, either allele frequency (allele size, RFLP or SNPs) or sequence-based approaches (e.g., Sunnucks 2000). Among them, coalescence-based approaches using nucleotidic polymorphisms from one or more species/lineages have arisen as a powerful tool for tracing historical demographic events, genetic exchange, and population isolation (e.g., Hey \& Nielsen 2004). Particularly powerful are coalescent analyses in a geographic context (i.e., phylogeography) with neutral markers lacking recombination. In these cases, gene genealogies and phylogenetic networks (Posada \& Crandall 2001) together with DNA sequence diversity indexes can enable the reconstruction of population histories and identification of the possible reduction and/or expansion of populations (e.g., Emerson et al. 2001). Comparative approaches using multiple codistributed species sharing congruent patterns of genetic structure between reciprocally monophyletic populations can reveal major isolating mechanisms or barriers to dispersal (Bermingham \& Avise 1986).

Mitochondrial genes are the most widely used genes for phylogeographic analyses in animals (Avise 1998). The absence of recombination due to the maternal inheritance of the mitochondria (but see Skibinski et al. 1994), the supposed neutrality, relatively rapid mutation rates makes it sensitive to population subdivision (Avise 1998) and ease of data generation of this haploid sequence (Folmer et al. 1994) provide major advantages to using this gene. The use of these genes has been recently found to be controversial for the inference of population size and past demographic events because of the recurrence of possible 
70 selective sweeps, which mimic the reduction of the effective population size following a bottleneck or a founder event (Bazin et al. 2006) and the need for unlinked multi-loci datasets. However, even if rarely done in the same study, comparison across multiple coliving species could help in disentangle demographic events from selective sweeps. For example, Lessa et al. (2003) showed concordant evidence for shared demographic expansion in North American mammals by comparing different species using the mitochondrial Cytochrome b gene only and Smith \& Farrell (2005) revealed concomitant range expansions in Moneilema gigas and M. armatum beetles using the Cytochrome Oxidase I gene (mtCOI) gene.

Deep-sea hydrothermal vents on intermediate to fast-spreading mid-ocean ridges provide opportunities for testing shared vicariant events and concomitant demographic changes as populations form metapopulations subjected to frequent local extinctions and bottlenecks due to the recurrence of eruptive activity (Haymon et al. 1991; Jollivet et al. 1999; Tunnicliffe et al. 1997). Vent habitats are distributed along oceanic ridges where sulfide-rich fluid emissions are ephemeral both in time (years to a few decades; Shank et al. 1998) and space (Jollivet et al. 1999). Distances between sites vary from tens to hundreds of kilometres and can play an important role in population differentiation and allopatric speciation. Previous studies have focussed on the role of plate tectonics in favoring allopatry and subsequent secondary contacts across topographic (transform faults) and/or oceanographic (gyres) barriers (O'Mullan et al. 2001; Hurtado et al. 2004; Young et al. 2008; Faure et al. accepted). Moreover, at the scale of geological times, vent field (cluster of sites) displacements imposed by the dynamics of the underlying magmatic chamber are likely to favor a succession of isolation phases and secondary contacts (Jollivet et al. 1999). Plate 
94 tectonics is thus one of the major forces acting on faunal composition, distinguishing seven hydrothermal vent biogeographical provinces (Tunnicliffe 1991; Van Dover et al. 2002; Bachraty et al. 2009). Differences in the faunistic composition of vent communities at a global scale are however difficult to reconcile with the origin of speciation processes, which in turn need to be assessed at a more restricted spatial scale (i.e., the ridge scale). At this level of spatial organization, well-dated topographical discontinuities that offset the ridge (like transform faults, overlapping spreading centers or microplates) are largely responsible for bottom current disruption, favoring breaks in gene flow that may contribute to vicariance affecting nearly the entire regional species pool. In this geological context, the concomitant isolation of taxa may be followed or not by secondary contacts and population admixtures, the extent of a contact zone and its age mostly depending on both the life-history traits of each species and the level of habitat connectivity. Comparative phylogeographic analyses are thus helpful to identify potential sources of vicariance shared between species. Sequencebased methods based on coalescence theory are then necessary to detect the major ecological/tectonic events that might have influenced most co-evolving species population dynamics and subsequently blurred the phylogenetic information (i.e., divergence time). Based on faunal composition, the East Pacific Rise (EPR) has been recently sub-

111 divided into two different biogeographic provinces one from each side of the equator

112 (Bachraty et al. 2009), suggesting the presence of a potential barrier to gene flow at this

113 latitude. The equatorial barrier was however established on faunal differences between the

114 two communities based on the presence/absence of species. The present study aims at

115 examining whether this hypothesized biogeographic break gave rise to distinct genetic

116 divisions among vent species that co-occur in both Northern and Southern EPR. Indeed,

117 Burton (1998) showed that the abrupt change in the faunal composition of nearshore marine 
118 communities at Point Conception (California) did not always correlate with the genetic

119 isolation of its species components. If the biogeographic split coincides with a species genetic

120 break, two additional questions must be addressed: 1) is the position of the break at the same

121 geographic location for all species, and 2) is the timing of separation consistent among taxa

122 and thus represent a 'true' vicariant event between communities. Differences in species'

123 dispersal capabilities may indeed allow them to track spreading vent fields differentially after

124 the time of isolation. Finally, the study also aims to examine hypotheses regarding the

125 possible stepwise population expansion in a given direction along the EPR. Gene flow

126 asymmetries across the barrier would provide useful information about the history of

127 colonization along ridges, particularly if taxa display similar patterns of directional gene

128 flow. Comparative phylogeographic analysis of mtCOI sequences from seven broadly-

129 distributed species from three different taxonomic groups (three gastropod limpets, three

130 polychaetes and one bivalve species) was therefore conducted to test for shared vicariant

131 events and demographic histories among the vent fauna. 


\section{Materials and methods}

Biological specimens and molecular methods

135 Specimens from seven morphologically well-described species (Bathymodiolus thermophilus,

136 Alvinella pompejana, Hesiolyra bergi, Branchipolynoe symmytilida, Eulepetopsis vitrea

137 Lepetodrilus ovalis, Lepetodrilus elevatus) were collected along the East Pacific Rise during either the Nautile or DSV Alvin submersible expeditions. Nine hydrothermal vent localities were sampled in 1999, 2002, 2003 and 2004 (Table 1). The primary biological and habitat characteristics of the seven sampled species are summarized in Table 2. Animals were collected from sulfide chimneys, mussel beds, and vestimentiferan assemblages by grabbing the fauna with the submersible manipulator arm and storing them in an insulated box until the sub was recovered on board the support ship. Animals were individually preserved in absolute alcohol.

Genomic DNA of the three species of gastropods (L. elevatus, L. ovalis and E. vitrea) was extracted using NucleoSpin Tissue-Kit (Macherey-Nagel) following the manufacturer's

147 instructions. Genomic DNA of polychaetes (A. pompejana, B. symmytilida, and H. bergi) and the bivalve $B$. thermophilus was extracted using a CTAB extraction procedure (Doyle \&

149 Dickson 1987). Tissues were digested in $600 \mu \mathrm{l}$ of a $2 \%$ CTAB buffer solution (1.4 M NaCl,

$150 \quad 0.2 \%$ 2-mercaptoethanol, $20 \mathrm{mM}$ EDTA, $100 \mathrm{mM}$ Tris- $\mathrm{HCl} \mathrm{pH} \mathrm{8,} 0.1 \mathrm{mg} \cdot \mathrm{ml}^{-1}$ proteinase K)

151 for two hours at $60^{\circ} \mathrm{C}$. DNA was then purified by adding Chloroform-Isoamyl alcohol (24:1)

152 and precipitated together with $1 \mathrm{ml}$ of $100 \%$ isopropanol at $-20^{\circ} \mathrm{C}$ for two hours. Finally,

153 DNA pellets were washed with $70 \%$ ethanol and re-suspended in $50 \mu$ l of sterile $\mathrm{H}_{2} \mathrm{O}$. Species-specific primers (Table 3) were developed using a first set of sequences 
156 mitochondrial Cytochrome Oxidase I primers (LCOI, HCO1, Folmer et al. 1994). This

157 procedure strengthened the amplification of DNA for B. thermophilus, A. pompejana, B.

158 symmytilida, H. bergi and L. elevatus. Polymerase chain reaction amplifications were

159 performed in a $25 \mu 1$ reaction volume containing $1 \mathrm{x}$ reaction buffer (supplied by

160 manufacturer), $2 \mathrm{mM} \mathrm{MgCl}, 0.12 \mathrm{mM}$ each dNTPs, $0.5 \mu \mathrm{M}$ each primers, $20 \mu \mathrm{g} . \mathrm{ml}^{-1}$ Bovine

161 Serum Albumin, $0.75 \mathrm{U}$ Thermoprime plus DNA polymerase (Thermo Scientific), $2 \mu 1$ of

162 template DNA and sterile $\mathrm{H}_{2} 0$. Thermal cycling parameters used an initial denaturation at

$16394^{\circ} \mathrm{C}$ for $2 \mathrm{~min}$, followed by 40 cycles at $94^{\circ} \mathrm{C}$ for $35 \mathrm{~s}$, appropriate annealing temperature for

$16435 \mathrm{~s}$ (Table 3), and $72^{\circ} \mathrm{C}$ for $1 \mathrm{~min} 20 \mathrm{~s}$, before a final 10 -min extension at $72^{\circ} \mathrm{C}$.

165 PCR products were purified with Millipore Montage ${ }^{\mathrm{TM}} \mu \mathrm{PCR}_{96}$ Cleanup kit and

166 sequenced on an ABI 3130XL DNA analyser using BigDye® Terminator v3.1 (Applied

167 Biosystems) sequencing chemistry following the manufacturer's protocol. Sequences were

168 proofread in Chromas version 2.23 (http://www.technelysium.com.au/chromas.html) and

169 aligned in BioEdit version 6.0.6 (Hall 1999).

170

171 Phylogeographic structure and divergence

172 For each species, number of haplotypes $(h)$ and haplotype diversities $(H d)$ within each

173 hydrothermal vent site were determined using DNAsp 4.10.3 (Rozas et al. 2003). The

174 genealogical relationships among haplotypes were estimated using the median joining

175 algorithm (Bandelt et al. 1999) of Network software (version 4.5.0.0; www.fluxus-

176 engineering.com), allowing for the definition of clades (based on divergence up to $0.5 \%$ ).

177 The haplotype diversity $(H d)$, nucleotide diversity $\left(\pi_{n}\right)$ and Watterson's theta $\left(\theta_{w}\right)$ were

178 estimated within each divergent clade using DNAsp 4.10.3. 

(ancestral) haplotype-frequency distributions for each locality. In order to detect putative 181 geographic barriers to gene flow, F-statistics ( $\phi_{\text {st }}$; Hudson et al. 1992) were computed via 182 DNAsp 4.10.3 with a sliding window of 3 populations from $21^{\circ} \mathrm{S}$ to $21^{\circ} \mathrm{N}$ in order to avoid sampling size effect. For example, for $E$. vitrea, the $\phi_{\text {st }}$ calculation grouped populations from $21^{\circ} \mathrm{S}-18^{\circ} \mathrm{S}-17^{\circ} 34^{\prime} \mathrm{S}$, the second one from $18^{\circ} \mathrm{S}-17^{\circ} 34^{\prime} \mathrm{S}-17^{\circ} 25^{\prime} \mathrm{S}$ and so on until reaching the last grouping $9^{\circ} \mathrm{N}-13^{\circ} \mathrm{N}-21^{\circ} \mathrm{N}$. Groups were not always the same among species depending on the locality sampling schedule (sites without sample). For each sliding window, departure of the F-statistic value from zero was tested using a permutation test. Clade admixtures (i.e. presence of divergent clades in the population) were examined for each population by looking at the proportion of synthetic haplotypes typifying each mitochondrial lineage in order to reveal potential geographic clines. Substitution rates consistent with a molecular clock were tested for each species via the BEAUti/BEAST 1.4.8 MCMC package (Drummond \& Rambaut 2007) using a subset of 15-20 informative sequences. A GTR $+\mathrm{G}+\mathrm{I}$ substitution model was chosen to run an uncorrelated lognormal relaxed molecular clock model using a constant population size coalescent with 10,000,000 steps, a sampling every 500 steps and a burnin of 100,000 steps to reach convergence. The goodness of fit to a strict clock model was performed by

197 examining of the posterior distribution of the standard deviation of the uncorrelated lognormal relaxed clock (Std ulrc). Divergence times $(\mathrm{T})$ were then estimated between clades for each species when possible using the formula $T=D /(2 r)$, where $D$ is the average divergence between clades and $\mathrm{r}$ the evolutionary rate per site per million years (Kumar et al.

201 1996). Three independent clock calibrations were previously performed on mtCOI, using known historical vicariance events of the ridge system that may have affected vent population 
203 demography: (1) the Farallon ridge subduction under the American plate, 28.5 Mya

204 (Chevaldonné et al. 2002), the formation of the Cascadia depression in the $450 \mathrm{~km}$-long

205 Blanco transform fault, 5 Mya (Johnson et al. 2006) and the formation of the Easter

206 microplate, 5.9 Mya (Faure et al. accepted). Calibrations led to the estimation of a mutation

207 rate of $2.2 \%, 2.8 \%$ and $3.8 \%$ for several vent annelids, Lepetodrilus limpets and

208 Bathymodiolus bivalves, respectively, indicating a close evolution rate across vent taxa for

209 the mtCOI gene. Consequently, estimations of divergence times between each taxon-pair

210 were performed using a consensual (2.8\%) mutation rate for the seven species.

211 To test for simultaneous divergence across clade pairs and common barriers to gene

212 flow among the seven species, an integrative approach using the MsBayes Approximate

213 Bayesian Computational (ABC) software (Hickerson et al. 2006b) was performed. The ABC

214 method simulates sequence datasets for a series of taxon pairs that fit a divergence population

215 model in which one ancestral population of size $\left(\mathrm{N}_{\mathrm{A}}\right)$ splits into two daughter populations a

216 and $b$ (of size $\mathrm{N}_{\mathrm{a}}$ and $\mathrm{N}_{\mathrm{b}}$ ) that independently endure a bottleneck of varying length $\tau^{\prime}$ (and

217 leading to actual sizes of $\mathrm{N}_{\mathrm{a}}$ ' and $\mathrm{N}_{\mathrm{b}}{ }^{\prime}$ ). Runs consist of three steps, allowing for the

218 estimation of inter-species parameters (i.e., hyperparameters such as the number of possible

219 divergence times $(\Psi)$ across taxon pairs, and the corresponding mean $(\mathrm{E}(\tau))$ and variance $(\Omega)$

220 of the divergence time $\tau$ ). First, a vector of observed summary statistics is obtained from the

221 observed dataset of each taxon pair. Second, through a series of hundreds of thousands of

222 replicates, the hyperparameters and sub-parameters that typify the coalescent model are

223 randomly drawn from hyper-prior and a sub-prior distributions in order to simulate a

224 corresponding finite sequence dataset for the Y taxon pairs. These simulated datasets are then

225 used to calculate a series of pseudo-summary statistics. These pseudo-summary statistics are

226 compared to the observed ones to produce an approximate sample of simulations (i.e., 
227 simulations that yield the nearest summary statistics values to the observed ones), that is then used to draw the posterior distributions of the hyper- and sub-parameters of the taxon pairs following an arbitrary rejection/acceptance ratio of 0.1-0.2 and a local weighted linear 230 regression. Twenty 329 bp- long sequences per clade constituted the input dataset. Because of a

232 lack of transversion in the between-clade divergence of some species, the transitiontransversion ratio was fixed to two (Jukes \& Cantor 1969). Joint prior distributions were used to perform 500,000 simulated draws. Out of these simulated draws, the closest to the observed dataset $(1,000)$ were used to define the joint posterior distribution. Upper bounds for the prior population mutation parameter for the ancestral population size $\left(\theta_{\mathrm{A}}\right)$ were chosen to be equal to 5 given the observed pairwise differences within clades (Hickerson et al.

2006b). These parameters were unchanged across runs allowing the cross-taxa comparison of results. $\mathrm{ABC}$ analysis was run on the seven species without any constraint on the number of

240 divergence times ( $\Psi$ ) to estimate the hyperparameters. ABC analysis was also performed

241 fixing $\Psi=2$ because obtained $\Psi$ values were greater than 1 . A final ABC analysis was

242 computed on species after suppressing the pair-clade L. elevatus (for which divergence

243 between clades was considered extremely high), without any constraint on $\Psi$.

Demographic history

246 Significantly non-null Tajima's $D$ and its derived statistics (e.g., the Fu \& Li's F) have been

247 widely used to trace back demographic events (Glinka et al. 2003; Akey et al. 2004) providing that the studied gene region evolved under a lack of selective pressures. In order to test the hypothesis that vent fauna have undergone demographic changes in response to

250 shared vicariant events, Tajima's (1989) statistic $D$ was estimated (using DNAsp 4.10.3) 
251 within each species for both the southern and northern clades located from each side of the equatorial biogeographic break following results of Bachraty et al. (2009). Tajima's D departure from zero was tested by a two tailed test assuming that $D$ follows the beta distribution (Tajima 1989).

To further examine whether or not species endured the same demographic change, effective population size $\left(N_{e}\right)$ and the exponential population growth parameter $g$ were estimated from clades with significantly non-null Tajima's $D$ values using Fluctuate (version 1.4, Kuhner et al. 1998). This allowed for the timing of expansion to be generated, following the formulation $\theta(t)=\theta_{0} e^{-g \mu t}$ in which $\theta=N_{e} \mu$ with $\mu$ the mutation rate, $t$ the time elapsed (in generations) and $\theta_{0}$ the present state of $\theta$ for the clade under scrutiny. For each species,

261 Fluctuate analyses were run with different values of short (i.e., 10, 50, 100, 150) and long 262 (i.e., 2, 10, 20, 30) chains to evaluate convergence between runs. Sampling increment and the number of steps were respectively three and fifteen times greater than the number of sequences found within a clade for both short and long chains. To test if expansion signature was due to a wave of colonization (stepwise foundations) or from the recovering of a recent bottleneck, asymmetrical gene flow was checked across the barrier. For each species, the

267 sliding window of $\Phi_{\text {st }}$ was used to locate the barrier and populations were then separated into two geographic groups from each part of the barrier, respectively. Watterson's theta $\left(\theta_{w}\right)$ was calculated for each group using DNAsp 4.10.3 (Rozas et al. 2003) and used as a starting

270 parameter in Migrate 3.0.3 (Beerli \& Felsenstein 1999; 2001) to estimate the gene flow parameters $\left(\theta^{*} \mathrm{M}\right)$ with MCMC runs of 10 short and 3 long chains. 


\section{Results}

274

275

276

277

278

279

280

281

282

283

284

285

286

287

288

289

290

291

292

293

294

295

\section{Phylogeographic structure and divergence across taxon pairs}

For each species, the number of haplotypes $(h)$ and haplotype diversities $(H d)$ within each population were assigned (Table 1). Median-joining networks exhibited similar topological patterns across all species, but differed in their structure (Fig. 1). Two divergent clades were detected in all networks except for: 1) $H$. bergi, in which 3 were divergent but markedly rare haplotypes were found in two of the most southern populations; and 2) for the scaleworm $B$. symmytilida, in which connections are more complex with at least 9 nearly equally-frequent haplotypes. Clades were geographically structured (with the exception of B. symmytilida), in particular with regard to the geographic location of the equator (Fig. 1). In each network, at least the southern clade (B) displayed a 'star'-like topology, with one central and frequent (ancestral) haplotype surrounded by a crown of derived singletons or multiple singletons (see however B. thermophilus for the exception of two closely-related equally-frequent haplotypes in the southern lineage). Derived haplotypes were often "unique" within a given locality. The northern clade was more diversified with more distant ('older') COI lineages. Divergence between the northern and the southern clades ranged from $0.9 \%$ for B. thermophilus to $6.5 \%$ for L. elevatus. By comparison, divergence for the two most frequent haplotypes of the scaleworm B. symmytilida was only $0.4 \%$.

The geographic distribution of haplotypes (Fig. 1) together with $\Phi_{\mathrm{st}}$ differentiation tests (Fig. 2) allowed us to discriminate clear patterns of geographic isolation for all species. When grouping localities from south to north, the sliding-window $\Phi_{\text {st }}$ became significantly different from zero between $17^{\circ} \mathrm{S}$ and the equator in all species except $H$. bergi. Occurrence for possible admixtures between divergent haplotypes typifying each clade along the EPR 
was detected (Table 1). Except for B. thermophilus and L. ovalis, admixture is often caused by less than $10 \%$ of individuals inside the investigated populations.

The vent polychaete $A$. pompejana (Ap) and the gastropod limpet $E$. vitrea $(E v)$ both

299

300

301

302

303

304

305

306

307

308

309

310

311

312

313

314

315

316 displayed exactly the same network architecture (Fig. 1). Coalescence trees are separated into two distinct clades (A and $\mathrm{B})$ across the equator with $1 \%(\mathrm{Ap})$ and $0.9 \%(E v)$ mutations accumulated into the divergence, respectively. Just one sequence from the southern clade (B) of A. pompejana was sampled in the northern EPR.

The vent limpet $L$. elevatus (Le) also displayed a pronounced geographic structure with two highly-divergent clades (divergence $=6.5 \%$ ), however clades overlap on the northern part of the EPR at $9^{\circ} \mathrm{N}$ (Fig. 1). In the northern clade, the population from $21^{\circ} \mathrm{N}$ displayed only one haplotype (i.e., Hap 1, the most frequent one in other populations) leading to a significant pairwise $\Phi_{\text {st }}$ between these two disjunct vent fields with and without considering the presence of clade $\mathrm{B}$ at $13^{\circ} \mathrm{N}$. In the southern clade, the population from $9^{\circ} \mathrm{N}$ sharply differed from the SEPR ones by the presence of a unique haplotype (Hap 4) at a high frequency. This haplotype diverged from the most frequent (ancestral) one (Hap 3) by 3 mutations and possessed a crown of derived haplotypes, indicating that it had time to diversify since the southern versus northern isolation of lineages.

The bivalve B. thermophilus (Bt) and the gastropod L. ovalis $($ Lo ) showed a nearly similar but reverse situation in which haplotypes of one clade were distributed along the entire ridge system whereas haplotypes from the other clade A are restricted to the northern $(B t)$ or the southern $(L o)$ parts of the EPR.

The two other vent species, $H$. bergi $(H b)$, which lives in sympatry with $A$. pompejana, and B. symmytilida $(B s)$, which lives commensally with the bivalve $B$. thermophilus, were characterized by a lack of obvious differences across localities throughout 
the EPR (Fig. 1). However, three individuals of $H$. bergi located in the south part of the EPR exhibited haplotypes with a clear divergence of nearly $1 \%$ that may represent 'old' surviving mitochondrial lineages whereas an isolation-by-distance structure was observed in $B$. symmytilida.

Using Migrate 3.0.3, A. pompejana and E. vitrea displayed a nearly complete absence of mtCOI gene flow across the equatorial region, whereas other species showed high asymmetric gene flow (Table 4) from North to South for H. bergi and South to North for the remaining species.

For each species, standard deviation of the uncorrelated lognormal relaxed clock (Std ulrc) was closed to zero (mean ranged from 0.416 to 0.608 with maximum probabilities close to zero and upper HPDs under 1), indicating no mutation rate heterogeneity among clades. Thus, these datasets can be utilized for divergence time estimates that assume a constant rate. Clade splitting dates calculated with $0.28 \%$ per My and the $\mathrm{T}=\mathrm{D} /(2 \mathrm{r})$ formula leads to the following divergence times: $\mathrm{T}_{L e}=11.6 \mathrm{My}, \mathrm{T}_{L o}=3.6 \mathrm{My}, \mathrm{T}_{H b}=1.9 \mathrm{My}, \mathrm{T}_{A p}=1.8 \mathrm{My}, \mathrm{T}_{E v}=$ 1.6 My, $\mathrm{T}_{B t}=1.6 \mathrm{My}$, and $\mathrm{T}_{B s}=0.7 \mathrm{My}$. Estimates of $\Omega(=\operatorname{Variance}(\tau) / \mathrm{E}(\tau))$ and the number of shared vicariant events $\Psi$ with MsBayes using our 7 taxon pairs did not support a history of simultaneous divergence (Fig. $3 \mathrm{~A}, \mathrm{C}$ ). Indeed, the average $\Psi$ value (1.858) is close to 2, indicating the occurrence for two possible isolation times. Moreover, the amount of variance ( $\Omega=0.384$ ) is high, possibly indicating a biased estimation of the mean divergence time $\mathrm{E}(\tau)$ (= 1.521, corresponding to $1.65 \mathrm{My}$ using the $\mathrm{T}=(100 \mathrm{E}(\tau)) /(\mathrm{r} *$ length of gene) equation (Hickerson et al. 2006a). Simulating vicariance events across the seven taxon pairs by fixing $\Psi=2$ indicated that six species have a simultaneous divergence time (with $\mathrm{E}\left(\tau_{1}\right)=1.088$ corresponding to $1.2 \mathrm{My}$ ) and one species had a greater divergence time (with $\mathrm{E}\left(\tau_{2}\right)=2.639$ corresponding to $2.9 \mathrm{My}$ ). The most divergent taxon-pair was expected to correspond to $L$. 
344 elevatus because this species shown the greatest single T value across species. Simulation

345 excluding L. elevatus pairs (Fig. 3 B, D) showed a clear-cut estimate of $\Psi$ nearly equal to one

346 (1.316) together with a markedly small variance $(\Omega=0.047<0.1)$. This latter estimate seems

347 to be robust, if the ancestral coalescent variance has a larger effect on the total genetic

348 divergence when divergence times are recent: a plausible explanation for EPR vent fauna in

349 light of the allopatric distribution across the equator. Here, the high variance of coalescent

350 estimates across taxon pairs was greatly compensated by the choice of the prior for $\theta_{\mathrm{A}}(0.5-$

351 5), highly stringent boundaries for this parameter being the consequence of the exceptionally

352 small ranges of observed pairwise differences within populations within each species pair.

353 Simultaneous divergence time $\mathrm{E}(\tau)$ was estimated to 1.187 , corresponding to a vicariant event

354 1.3 Mya. Divergence time (1.1 Mya using the $\mathrm{T}=\mathrm{D} / 2 \mathrm{r}$ equation) between Hap 3 and Hap 4

355 for L. elevatus was congruent with this simultaneous divergence time estimated for the six

356 other species, suggesting that all species were subjected to this vicariant event 1.3 Mya.

357 Results using BEAST were consistent with a common and recent vicariant event for all taxa

358 (including the southern lineage of L. elevatus) with average times of the most recent common

359 ancestor $\left(\mathrm{T}_{\mathrm{MRCA}}\right.$ ) ranging from $9.210^{-4}$ to $2.310^{-3}$ with a strong overlapping of HPDs.

360

361 Shared demographic histories in the South

362 To examine how clades evolved after being putatively isolated, Tajima's D was calculated for

363 each clade separately over the seven species pairs. Results (Table 5) indicated a difference

364 between the southern and northern clades. Tajima's D was always significantly negative in

365 the southern clade regardless of the species analyzed. A significant excess of rare variants

366 was also detected in the polychaetes $H$. bergi and B. symmytilida for which only one clade

367 was detected over the entire range. Moreover, when only considering populations without

368 admixture (Table 1), 25\%, $7 \%$ and $42 \%$ of populations had pairwise distributions differing 
369 significantly from the neutral hypothesis in $21^{\circ} \mathrm{N}-13^{\circ} \mathrm{N}, 9^{\circ} \mathrm{N}-14^{\circ} \mathrm{S}$ and $17^{\circ} 25^{\prime} \mathrm{S}-21^{\circ} \mathrm{S}$ regions,

370 respectively. Fluctuate analyses of the southern lineages (Fig. 4; using 100 short and 20 long

371 chains allowing convergence between runs for all species) estimated the beginning of a

372 global population expansion between 100,000 to 300,000 generations for all species except $B$.

373 symmytilida ( 1 million generations), with exponential population growth parameters $g$

374 ranging from 3,640 (L. elevatus) to 10,000 (H. bergi) when discarding B. symmytilida $(\mathrm{g}=$ $3752,160)$. 
377 Discussion

378 The seven deep-sea hydrothermal-vent species studied here possess different life-history

379 traits (Table 2), which are likely to influence their ability to expand their range and colonize

380 new localities. Despite biological disparities across species, mtCOI network topologies

381 yielded similar topologies - two divergent clades located in Northern and Southern EPR,

382 respectively, with only one exception, the commensal scaleworm B. symmytilida. Similar

383 topologies raise the question of whether the equatorial barrier previously described by

384 Bachraty et al. (2009) may have played a role in promoting a genetic break(s) across vent

385 species and subsequent gene flow limitations after the isolation of populations. In order to

386 test the 'vicariance' hypothesis, two main questions need to be answered: (1) did ancestral

387 species split at the same time and (2) was the barrier impermeable enough to impose the same

388 exact geographic patterns across the northern and southern vent lineages.

389

390 Number of splitting events in vent populations along the East Pacific Rise

391 In order to date vicariant events, the most currently used approaches consist of: 1) estimating

392 divergence times for each taxon-pairs; 2) comparing these dates across taxa accounting for

393 stochastic processes associated with the coalescence process; and 3) estimating the

394 demographic evolution of populations. This technique has been widely used to propose

395 vicariant events when speciation has occurred in the distant past (several millions years) or

396 when the target taxa represent conspecific species displaying the same life-history traits

397 across the same habitat. For example, simultaneous vicariant events have been documented

398 for coastal invertebrates inhabiting sediments along the European coasts of the North Atlantic

399 (Jolly et al. 2006) or the intertidal limpets separated across the Greater Cook Strait in New 
400 Zealand (Goldstien et al. 2006). In our case, the vicariance date of 11.6 millions years

401 estimated for L. elevatus coincides with two cryptic, possibly hybridizing, species detected by

402 Matabos et al. (2008) at 950N/EPR using allozymes and mtCOI sequences. However,

403 divergence times of the other remaining species are more recent and markedly close to each

404 other (from 3.6 Mya for L. ovalis to 1.6 Mya for B. thermophilus, 0.7 Mya for $B$.

405 symmytilida), suggesting that they may be the result of a same vicariant event.

406 However, testing whether co-distributed taxa share a common history of simultaneous

407 vicariance just by superimposing divergence times may lead to erroneous conclusions if the

408 vent community mixes species groups of different origins possibly via arriving into the ridge

409 system at different times. According to Hickerson et al. (2006b), variation between estimated

410 divergence times is largely explained by the mutational and coalescent variance. A recent

411 approach (Hickerson et al. 2006b) allows testing simultaneous divergence using Approximate

412 Bayesian Computation (ABC) by incorporating differences in the demographic history of

413 each sister population during the isolation process. Simulations using our seven taxon-pairs

414 indicated two possible splitting events (simulation without fixing $\Psi$ ), with the most recent

415 event affecting six species and the second one with a much older divergence time (simulation

416 with $\Psi=2$ ), affecting only one species, L. elevatus according to the previous species-by-

417 species estimation of divergence times. Although the most ancient divergence time estimated

418 for one species (L. elevatus) seems to be underestimated (2.9 My), the simultaneous

419 divergence time (1.2 My) estimated with $\Psi=2$ is consistent with the 1.3 My detected for the

420 most recent event when using $\Psi=1$ and the six remaining taxon-pairs. Moreover, L. elevatus

421 divergence between Hap 3 and 4 (1.1 Mya) inside the clade B are congruent with this

422 simultaneous divergent time, indicating that L. elevatus was submitted to this more recent

423 isolation event as well. Consequently, results are congruent with the hypothesis of two 
424 independent isolation events: 11.6 Mya for L. elevatus and 1.3 Mya for the other taxon-pairs.

425 Because allopatric speciation is usually caused by gene flow disruption due to

426 physical/tectonic barriers that modify hydrothermalism along ridge axes (Jollivet 1996), the

427 two possible splitting dates sub-dividing these vent species into two distinct phylogeographic

428 clades are likely explained by the formation of geological discontinuities that progressively

429 offset the ridge crest.

430

431 Geological barriers to gene flow along the East Pacific Rise

432 Plate tectonics most likely influence genetic structure and speciation of the hydrothermal vent

433 fauna, but the exact events are tough to pin point. Modeling the formation of the East Pacific

434 ridge system based on fossil records and magnetic/gravimetric anomalies suggested that the

435 subduction of the Farallon plate under the American plate provoked multiple reorganizations

436 of the now-extinct Pacific/Farallon ridges while forming the present East Pacific Rise

437 (Mammerickx et al. 1980). Two major co-occurring tectonic events could coincide with the

438 divergence date causing the L. elevatus split 11.6 Mya: (1) the Bauer microplate rotation and

439 (2) the Mathematician Ridge reorientation. The formation of the Bauer Overlapping

440 Spreading Centre initiated about $17 \mathrm{Mya}$ (at latitudes located between 10 to $15^{\circ} \mathrm{S}$ ), evolved

441 into a microplate between 15-11 Mya (Eakins \& Lonsdale 2003). Such reorganization

442 provoked ridge offset and the formation of two parallel active ridges that could have been

443 responsible for modifying the bottom current patterns in this region and subsequently the $L$.

444 elevatus divergence. During the same period (12.5-11 Mya, Mammerickx \& Klitgord 1982),

445 the Mathematician Ridge situated further North $\left(12^{\circ} \mathrm{N}\right.$ to $\left.17^{\circ} \mathrm{N}\right)$ was subjected to abrupt

446 changes in magnetic and bathymetric orientations, provoking the fossilization of transform

447 faults and the formation of a parallel ridge system, the Moctezuma trough in this northern 
448 region (Mammerickx \& Klitgord 1982). Because the Mathematician ridge reorganization

449 event appears to be much closer to latitudes at which the two present divergent lineages

450 overlap (between $9^{\circ} \mathrm{N}$ and $13^{\circ} \mathrm{N}$ ), this latter scenario seems to be more consistent with the $L$.

451 elevatus split.

452 The seven-studied vent species seem to share a simultaneous vicariant event $\sim 1.3$

453 Mya. Moreover, this vicariant event coincides with a significant north/south differentiation of 454 vent populations for all species with the exception of the polychaete $H$. bergi. However, this 455 polychaete species displays three divergent haplotypes sampled at the most southern sites, 456 suggesting that either the second clade was under-sampled or went nearly extinct. Even if $B$.

457 symmytilida and L. elevatus seem to display a more complex population history, both species 458 conform to the hypothesis of a recent North/South isolation. This is particularly clear when 459 considering the genetic differentiation observed between populations located at $9^{\circ} \mathrm{N}$ and $14^{\circ} \mathrm{S}$ 460 for B. symmytilida and the southern lineage (clade B) of L. elevatus at the same geographical 461 sites. By superimposing geographic distribution of haplotypes and the position at which 462 genetic differentiation increases significantly across species, this barrier is likely to be 463 positioned between the Equator and $17^{\circ} \mathrm{S}$, and defines a clear transition zone between the 464 Northern and Southern EPR. Most transform faults located between $9^{\circ} \mathrm{N}$ and $17^{\circ} \mathrm{S}$ (i.e., 465 Quebrada/Discovery/Gofar fracture zone system, or Wilkes and Garrett transform faults) 466 deeply offset the ridge axis into separate segments around 1 to 2 millions years ago (Kureth 467 \& Rea 1981; Naar \& Hey 1989; Francheteau et al. 1990), a scenario consistent with the 468 simultaneous 1.3 Mya divergent time. As an example, the 450-km-long Blanco Transform 469 fault is known to be responsible for the speciation of Lepetodrilus fucensis and L. gordensis 470 (Johnson et al. 2006) with a divergence of $7.3 \%$ on the mtCOI gene and allele frequency 471 inversion at the phosphoglucomutase gene. However, the impact of this fault as a barrier to 
gene flow was less intense for the tubeworm Ridgeia piscesae, for which isolation did not

473 lead to reciprocal monophyletic clades but only abrupt haplotype frequency differentiation in populations located at each part of the ridge offset (Young et al. 2008).

The slow and progressive formation of a tectonic barrier (rate at which a ridge offset is typically $5-10 \mathrm{~cm} /$ year), could explain why slight discrepancies in population differentiation still hold across species, with some species able to cross the barrier when others are not (Knowlton \& Weigt 1998). The slight differences observed in the barrier positioning therefore may be attributable to differing dispersal capabilities. Indeed, egg size, egg vitellogenin content, and larval developmental mode (see Table 2) are good apparent indicators of dispersal capabilities and vary greatly across species. These characteristics affect the buoyancy of propagules and are likely to change the vertical dispersal of a larva in the water column (e.g., Mullineaux et al. 2005). Larvae could be thus subjected to different water currents and subsequent divergent trajectories. This may be particularly the case of Bathymodiolus bivalves which have planktotrophic larvae able to reach the upper water column (Arellano \& Young 2009) as opposed to Lepetodrilus gastropods whose larvae are mainly found beneath hydrothermal plume layers, less than 200 meters above the seafloor (Mullineaux et al. 2005). The extremely great size of mature oocytes $(400 \mu \mathrm{m})$ of the scaleworm Branchipolynoe spp. may also explained why this species is so weakly affected by

490 the equatorial barrier as large yolky eggs may delay larval metamorphosis for months

491 (Jollivet et al. 2000). The frequency of available vent habitat may also affect the ability of vent species to cross the barrier, as diffuse venting systems are more prevalent along the ridge compared to vent chimneys. However, the habitat distribution does not seem to play an important role to this extent as lineages from the two chimney-living species ( $A p$ and $H b)$ 495 have a markedly contrasted geographic range. 
Regardless of the species, the precise spatial positioning of the barrier remains

497 difficult to establish, firstly because some of these barriers may have disappeared (i.e., the

498 Bauer microplate) and, secondly because migration events and subsequent secondary contacts

499 likely mask the exact position of the barriers. Secondary contact zones detected in this study

500 often display clines of clade-specific haplotype frequencies (responsible for north/south EPR

501 differentiation). Such clines have been detected particularly in L. ovalis and B. thermophilus

502 and might be attributed to preferential migration routes along the EPR, as suggested by the

503 strong South to North asymmetric gene flow revealed by Migrate results. However,

504 differential lineage extinctions between northern and southern EPR (regional extinctions of $L$.

505 ovalis clade B in northern EPR and/or B. thermophilus clade A in the southern EPR) could

506 also explain such haplotype distributions.

507

508

Evidence for simultaneous population expansions in the south

509 Comparing haplotype coalescence trees and overall gene diversities between reciprocal

510 monophyletic clades of the examined vent taxa (with exception of $H$. bergi and $B$.

511 symmytilida for which a single clade is preponderant) indicated large discrepancies between

512 the northern and southern lineages. Star-like topologies together with reduced gene diversities

513 were indeed observed for southern lineages (generally not for the northern ones) and are

514 strongly suggestive of non-equilibrium dynamics. These results were supported by significant

515 negative Tajima's D for the southern clades. Furthermore, a greater proportion of populations

516 showed departure to equilibrium between $17^{\circ} 25^{\prime} \mathrm{S}$ and $21^{\circ} \mathrm{S}$ when compared to the most

517 northern populations. These departures to equilibrium may be explained by either a recent

518 demographic expansion along the Southern EPR (sensu Harpending et al. 1998) or

519 alternatively recurrent selective sweeps at the mitochondrial locus (Bazin et al. 2006). 
520 However, the positive selection hypothesis here imposes that a series of nearly-simultaneous

521 fixations of advantageous alleles co-occurred in different species, and only for the most

522 southern cryptic lineage: a situation in which mitochondria would have been sensitive to

523 positive fixation and able to sweep at an extremely high rate in the south but not in the north.

524 In addition, Fluctuate analyses performed on our seven vent taxa revealed a nearly

525 simultaneous expansion of southern populations for all species except the commensal

526 scaleworm B. symmytilida. Altogether the selective hypothesis is highly unlikely because

527 simultaneous selective sweeps across different vent taxa is highly improbable.

528 If we accept the idea that populations expanded on one side of the barrier after having

529 been separated about 1.3 Mya, the nearly simultaneous expansion would date back to 100,000

530 to 300,000 generations for all species except B. symmytilida (around 800,000 generations).

531 Making the assumption that one to two generations occur per year for nearly all vent species,

532 the date of expansion would fall in the last 500,000 years and coincide well with an

533 expansion subsequent to the splitting of the two vicariant lineages. Two hypotheses are

534 proposed: (1) this demographic expansion coincides with a geographic expansion of most

535 lineages to the south by subsequent founder events until discouraged by the Eastern

536 Microplate around $23^{\circ} \mathrm{S}$; and/or (2) the southern EPR endured a large catastrophic/eruptive

537 event that destroyed most of the vent fauna throughout the region, thus causing a large

538 bottleneck, about 0.5 Mya. The second hypothesis appears to be more probable, as eruptive

539 events can be frequent occurrences along the EPR, with the observation of two eruptions in

540 the last twenty years near 950N (Haymon et al. 1993; Cowen et al. 2007). Such an

541 assumption is also in agreement with the lack of concordant asymmetric flow across species

542 from north to south. Indeed, vent species did not display similar patterns of orientated gene

543 flow across the barrier, whereby gene flow was mainly orientated in the opposite direction 
544 from south to north. Such eruptive events may also to be responsible for a possible bottleneck 545 at $21^{\circ} \mathrm{N}$ (only one haplotype has been sampled for L. elevatus). Multiple catastrophic events 546 along the southern EPR could therefore explain this cross-species demographical pattern.

547 Recent theoretical studies argue that mitochondrial genes may not be appropriate to

548 perform phylogeographic analyses despite some advantages such as the non-recombination of

549 the gene (Bazin et al. 2006). The present study illustrates the usefulness of mitochondrial

550 markers when used across a set of species sharing the same environment, regional

551 distribution, and more or less the same history. Comparing multiple phylogeographic patterns

552 can help in discriminating demographic versus selective effects, and thus yielding a better

553 understanding on the micro-evolutionary processes that shapie the geographic structure of

554 populations.

555

556 Acknowledgments

557 We thank the chief scientists and 'Nautile' and 'Alvin' crews for their technical support and

558 efforts during our oceanographic expeditions: HOPE99, PHARE2002 (F. Gaill and N.

559 Lebris), Extreme 2003 (AT11-4 cruise) and BIOSPEEDO2004. We are very grateful to

560 Stéphane Hourdez and Eric Thiébaut for collecting and sorting polychaetes and gastropods

561 and to Marjolaine Matabos for her help in the diagnosis of Lepetodrilid gastropods. We are

562 also truly indebted to the sequencing genomic plateform (GENOMER, Station Biologique de

563 Roscoff, France) for DNA direct sequencing. This work was supported by the GDR Ecchis,

564 ANR-06-BDV-005 (Deep Oases) and ANR-05-BLAN-0407 (Alvi_Stress_Adapt). S.

565 Plouviez was supported by a PhD grant from the Université Pierre et Marie Curie. T.M.

566 Shank was supported by the National Science Foundation (OCE-01-29394 and OCE-03-

567 16348) and a Fellowship from the Deep-Ocean Exploration Institute, Woods Hole 
568 Oceanographic Institution. 
569 Table 1 Location, size of faunistic samples, number of haplotypes and admixture between clades at population level along the East Pacific

570 Rise for the seven species.

$571 N$, number of mtCOI sequences used in the study per sample and species (Abs stands for the absence of the species at the studied site. 0

572 means that no sample could be collected although the species was observed at the site) including those coming from GenBank (in

573 brackets); $h$, number of haplotypes; $H d$, haplotype diversity; Adm, number of sequences from clade A / clade B; Bt, B. thermophilus; Ap, A.

574 pompejana; Hb, H. bergi; Bs, B. symmytilida; Ev, E. vitrea; Lo, L. ovalis; Le, L. elevatus

575

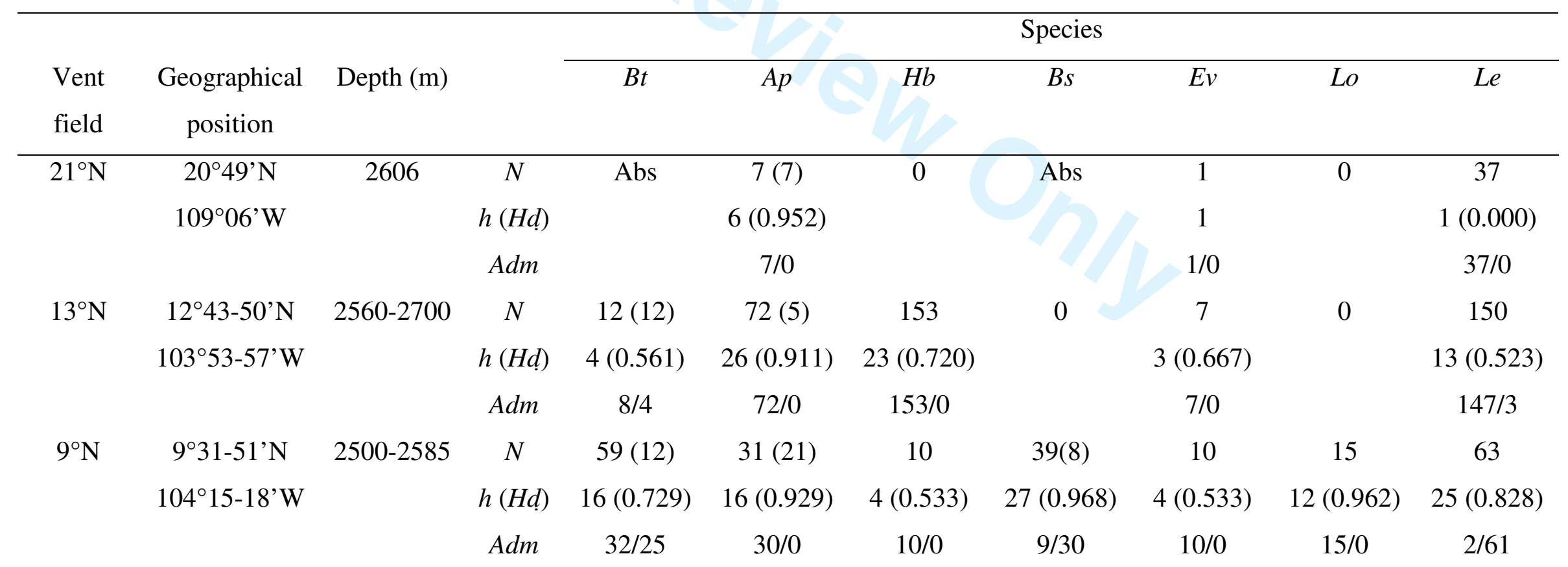




\begin{tabular}{|c|c|c|c|c|c|c|c|c|c|c|}
\hline \multirow[t]{3}{*}{$7^{\circ} \mathrm{S}$} & $7^{\circ} 25^{\prime} \mathrm{S}$ & $2735-2752$ & $N$ & $58(12)$ & 14 & 0 & 20 & 27 & 6 & 1 \\
\hline & $107^{\circ} 47-49 \mathrm{~W}$ & & $h(H d)$ & $21(0.837)$ & $7(0.758)$ & & $15(0.953)$ & $9(0.687)$ & $2(0.333)$ & 1 \\
\hline & & & $A d m$ & $22 / 38$ & $0 / 14$ & & $3 / 17$ & $0 / 27$ & $6 / 0$ & $0 / 1$ \\
\hline \multirow[t]{3}{*}{$14^{\circ} \mathrm{S}$} & $13^{\circ} 59^{\prime} \mathrm{S}$ & $2623-2632$ & $N$ & 30 & $23(3)$ & 8 & 17 & 48 & 22 & 44 \\
\hline & $112^{\circ} 29^{\prime} \mathrm{W}$ & & $h(H d)$ & $14(0.825)$ & $8(0.581)$ & $3(0.464)$ & $13(0.971)$ & $11(0.647)$ & $7(0.714)$ & $8(0.368)$ \\
\hline & & & $A d m$ & $0 / 30$ & $0 / 23$ & $8 / 0$ & $6 / 11$ & $0 / 48$ & $11 / 11$ & $0 / 44$ \\
\hline \multirow[t]{3}{*}{$17^{\circ} 25^{\prime} \mathrm{S}$} & $17^{\circ} 25^{\prime} \mathrm{S}$ & $2578-2590$ & $N$ & $33(12)$ & $51(21)$ & 0 & 29 & 72 & 52 & 49 \\
\hline & $113^{\circ} 12^{\prime} \mathrm{W}$ & & $h(H d)$ & $8(0.585)$ & $19(0.610)$ & & $22(0.982)$ & $17(0.725)$ & $18(0.749)$ & $10(0.489)$ \\
\hline & & & $A d m$ & $0 / 33$ & $0 / 51$ & & $4 / 25$ & $0 / 72$ & $7 / 45$ & $0 / 49$ \\
\hline \multirow[t]{3}{*}{$17^{\circ} 35^{\prime} \mathrm{S}$} & $17^{\circ} 35-36^{\prime} \mathrm{S}$ & $2591-2597$ & $N$ & 60 & 36 & 34 & 49 & 51 & 46 & 64 \\
\hline & $113^{\circ} 15^{\prime} \mathrm{W}$ & & $h(H d)$ & $24(0.817)$ & $10(0.483)$ & $7(0.373)$ & $30(0.957)$ & $15(0.503)$ & $13(0.650)$ & $17(0.588)$ \\
\hline & & & $A d m$ & $2 / 58$ & $0 / 36$ & $33 / 1$ & $7 / 42$ & $0 / 51$ & $5 / 41$ & $0 / 64$ \\
\hline \multirow[t]{3}{*}{$18^{\circ} \mathrm{S}$} & $18^{\circ} 26-37^{\prime} S$ & $2636-2680$ & $N$ & 30 & 29 & 11 & 29 & 47 & 24 & 0 \\
\hline & $113^{\circ} 23-24^{\prime} \mathrm{W}$ & & $h(H d)$ & $14(0.825)$ & $11(0.724)$ & $3(0.345)$ & $20(0.961)$ & $13(0.677)$ & $8(0.757)$ & \\
\hline & & & $A d m$ & $0 / 30$ & $0 / 29$ & $11 / 0$ & $6 / 23$ & $0 / 47$ & $5 / 19$ & \\
\hline \multirow[t]{3}{*}{$21^{\circ} \mathrm{S}$} & $21^{\circ} 25-33^{\prime} S$ & 2804-2840 & $N$ & 27 & 55 & 19 & 24 & 34 & 22 & 31 \\
\hline & $114^{\circ} 16-18^{\prime} \mathrm{W}$ & & $h(H d)$ & $12(0.818)$ & $14(0.613)$ & $3(0.292)$ & $19(0.982)$ & $15(0.779)$ & $9(0.745)$ & $6(0.353)$ \\
\hline & & & $A d m$ & $0 / 27$ & $0 / 55$ & $17 / 2$ & $2 / 22$ & $0 / 34$ & $3 / 19$ & $0 / 31$ \\
\hline
\end{tabular}


577 Table 2 Biological and ecological characteristic of the seven studied vent invertebrates

\begin{tabular}{|c|c|c|c|c|c|c|c|}
\hline Species & Fertilization & $\begin{array}{l}\text { Fecundity } \\
\text { (oocytes } \\
\text { female }^{-1} \text { ) }\end{array}$ & $\begin{array}{l}\text { Egg } \\
\text { size } \\
(\mu \mathrm{m})\end{array}$ & $\begin{array}{l}\text { Dispersal } \\
\text { mode }\end{array}$ & Reproduction & Habitat & Reference \\
\hline$B t$ & External & 1,000000 & 50 & $\begin{array}{l}\text { Plantoctrophic } \\
\text { larva }\end{array}$ & Discontinuous & Diffuse venting & $\begin{array}{c}\text { Le Pennec et } \\
\text { al. } 1984 ; \\
\text { Tunnicliffe } \\
\text { 1991; } \\
\text { Jollivet } 1996\end{array}$ \\
\hline$A p$ & Internal & 200,000 & 180 & $\begin{array}{l}\text { Lecithotrophic } \\
\text { larva }\end{array}$ & $\begin{array}{l}\text { Nearly- } \\
\text { continuous }\end{array}$ & Vent chimney & $\begin{array}{c}\text { Jollivet } \\
\text { 1996; } \\
\text { Chevaldonné } \\
\text { et al. } 1997 ; \\
\text { Faure et al. } \\
2007\end{array}$ \\
\hline$H b$ & & & & & & Vent chimney & Jollivet 1996 \\
\hline$B s$ & Internal & 1,000 & 400 & $\begin{array}{l}\text { Lecithotrophic } \\
\text { larva }\end{array}$ & $\begin{array}{l}\text { Continuous or } \\
\text { frequently } \\
\text { intermittent }\end{array}$ & $\begin{array}{c}\text { Palleal cavity } \\
\text { of mussels }\end{array}$ & $\begin{array}{c}\text { Van Dover et } \\
\text { al. 1999; } \\
\text { Jollivet et al. } \\
\text { 2000; } \\
\text { Plouviez et } \\
\text { al. } 2008\end{array}$ \\
\hline$E v$ & Internal & 200 & 230 & $\begin{array}{c}\text { Lecithotrophic } \\
\text { larva }\end{array}$ & Continuous & $\begin{array}{l}\text { Basaltic rocks } \\
\text { and mussel } \\
\text { shells }\end{array}$ & $\begin{array}{c}\text { Tyler et al. } \\
2008\end{array}$ \\
\hline Lo & Internal & 1,000 & 90 & $\begin{array}{l}\text { Lecithotrophic } \\
\text { larva }\end{array}$ & Continuous & Mussel shells & $\begin{array}{c}\text { Fretter 1988; } \\
\text { Mullineaux } \\
\text { et al. 1995; } \\
\text { Sadosky et } \\
\text { al. } 2002 ; \\
\text { Tyler } \text { et al. } \\
2008\end{array}$ \\
\hline Le & Internal & 1,000 & 90 & $\begin{array}{l}\text { Lecithotrophic } \\
\text { larva }\end{array}$ & Continuous & $\begin{array}{l}\text { Vestimentiferan } \\
\text { tubes and } \\
\text { mussel shells }\end{array}$ & $\begin{array}{c}\text { Fretter 1988; } \\
\text { Mullineaux } \\
\text { et al. 1995; } \\
\text { Sadosky et } \\
\text { al. 2002; } \\
\text { Tyler et al. } \\
2008\end{array}$ \\
\hline
\end{tabular}


578 Table 3 Species-specific primers

\begin{tabular}{llc}
\hline Species & Primer sequences $\left(5^{\prime}-3^{\prime}\right)$ & $T_{a}\left({ }^{\circ} \mathrm{C}\right)$ \\
\hline B. thermophilus & F: TGTGGTCTGGAATAATTGGAAC & 50 \\
& R: ATAAAAAGATGTATTRAARTGACG & \\
A. pompejana & F: TATTTGGTATTTGGGCAGGTC & 57 \\
& R: GATGGGTCGAAGAATGATGTG & \\
B. symmytilida & F: CCCTTTACTTTCTATTTGGC & 51 \\
& R: ATTTCGATCTGTTAGGAGTATG & \\
H. bergi & F: CATACAAATAGTGGTACTCGTTC & 51 \\
& R: TTCCTTTTCGGACTATGAG & \\
L. elevatus & F: TGARCTYGGACAACCRGGAG & 56 \\
& R: RGGGTCAAAGAARGARGTGTT &
\end{tabular}

$579 \mathrm{~F}$, forward primer; $\mathrm{R}$, reverse primer; $T_{a}$, annealing temperature 
580 Table 4 Theta $(\theta)$ and migration $\left(\theta^{*} \mathrm{M}\right)$ parameters in each species. Bt, B. thermophilus; Ap, 581 A. pompejana; Hb, H. bergi; Bs, B. symmytilida; Ev, E. vitrea; Lo, L. ovalis; Le, L. elevatus

\begin{tabular}{lccccccc}
\hline Parameters & $B t$ & $A p$ & $H b$ & $B s$ & $E v$ & $L o$ & $L e$ \\
\hline$\theta$ North population & 0.014 & 0.016 & 0.024 & 0.050 & 0.007 & 0.018 & 0.040 \\
$\theta$ South population & 0.034 & 0.024 & 0.009 & 0.065 & 0.030 & 0.018 & 0.013 \\
$\theta^{*}$ M North to South & 0.000 & 0.000 & 2.338 & 1.142 & 0.280 & 0.377 & 0.000 \\
$\theta^{*}$ M South to North & 21.676 & 0.572 & 0.000 & 90.882 & 0.000 & 15.292 & 28.077 \\
\hline
\end{tabular}


582 Table 5 Haplotype diversity $(H d)$, nucleotide diversity $\left(\pi_{n}\right)$, Watterson's theta per site from 583 number of segregating sites $\left(\theta_{w}\right)$, and Tajima's $D$ of clades from studied species and overall $584 \Phi_{\text {st }}$ values for each species

\begin{tabular}{|c|c|c|c|c|c|}
\hline Species/clade $\left(\Phi_{\text {st }}\right)$ & $n$ & $H d(\mathrm{SD})$ & $\pi_{n}(\mathrm{SD})$ & $\theta_{w}(\mathrm{SD})$ & $D$ \\
\hline \multicolumn{6}{|l|}{ B. thermophilus $\left(0.255^{* * * *}\right)$} \\
\hline Northern clade & 64 & $0.208(0.068)$ & $0.000(0.000)$ & $0.002(0.001)$ & $-2.011^{*}$ \\
\hline Southern clade & 245 & $0.812(0.019)$ & $0.003(0.000)$ & $0.016(0.004)$ & $-2.452^{* * * *}$ \\
\hline \multicolumn{6}{|l|}{ A. pompejana $\left(0.533^{* * * *}\right)$} \\
\hline Northern clade & 108 & $0.911(0.014)$ & $0.009(0.000)$ & $0.014(0.004)$ & $-0.983^{\mathrm{NS}}$ \\
\hline Southern clade & 210 & $0.618(0.040)$ & $0.002(0.000)$ & $0.015(0.004)$ & $-2.564^{* * * *}$ \\
\hline \multicolumn{6}{|l|}{ H. bergi $\left(0.018^{* *}\right)$} \\
\hline Major clade & 232 & $0.614(0.036)$ & $0.002(0.000)$ & $0.015(0.004)$ & $-2.379^{* *}$ \\
\hline Southern minor clade & 3 & - & - & - & - \\
\hline B. symmytilida $\left(0.031^{* * *}\right)$ & 208 & $0.970(0.005)$ & $0.007(0.000)$ & $0.022(0.005)$ & $-2.137^{* *}$ \\
\hline \multicolumn{6}{|l|}{ E. vitrea $\left(0.578^{* * *}\right)$} \\
\hline Northern clade & 18 & $0.562(0.134)$ & $0.002(0.001)$ & $0.005(0.003)$ & $-1.849^{*}$ \\
\hline Southern clade & 279 & $0.646(0.032)$ & $0.003(0.000)$ & $0.016(0.004)$ & $-2.369^{* *}$ \\
\hline \multicolumn{6}{|l|}{ L. ovalis $\left(0.484^{* * * *}\right)$} \\
\hline Northern clade & 51 & $0.722(0.047)$ & $0.003(0.000)$ & $0.004(0.002)$ & $-1.143^{\mathrm{NS}}$ \\
\hline Southern clade & 136 & $0.628(0.048)$ & $0.002(0.000)$ & $0.012(0.003)$ & $-2.477^{* *}$ \\
\hline \multicolumn{6}{|l|}{ L. elevatus $\left(0.900^{* * *}\right)$} \\
\hline Northern species & 186 & $0.432(0.036)$ & $0.001(0.000)$ & $0.005(0.002)$ & $-1.599^{\mathrm{NS}}$ \\
\hline Southern species & 253 & $0.590(0.037)$ & $0.003(0.000)$ & $0.016(0.004)$ & $-2.326^{* *}$ \\
\hline
\end{tabular}


587 Fig. 1 Median joining networks and haplotype frequency distributions of all sampled 588 populations for the seven species. Size of haplotype circles and connections are proportional 589 to number of sequences and mutation step, respectively. A and B represent the two divergent 590 clades for each species. On the haplotype-frequency distributions, shared haplotypes with 591 greater than $2 \%$ frequency within its corresponding clade were coloured. Private haplotypes 592 and shared haplotypes with lower than $2 \%$ frequency within its clade were put in white.

593 Bt, B. thermophilus; Ap, A. pompejana; Hb, H. bergi; Bs, B. symmytilida; Ev, E. vitrea; Lo, L. 594 ovalis; Le, L. elevatus 
595 Fig. 2 Distribution of $\Phi_{\text {st }}$ values calculating for groups of three populations using a sliding

596 windows as a function of distance to $21^{\circ} \mathrm{S}$. Each point represents $\Phi_{\text {st }}$ values relative to a

597 barycentric position of the three vent fields latitudes used in the sliding window. ${ }^{*} P<0.05$.

598 Bt, B. thermophilus; Ap, A. pompejana; Hb, H. bergi; Bs, B. symmytilida; Ev, E. vitrea; Lo, L. 599 ovalis; Le, L. elevatus 
600 Fig. 3 (A, B) Three-dimensional joint posterior probability densities for $\mathrm{E}(\tau)$ and $\Omega$. (C, D) 601 Posterior probability densities for $\Psi$, the number of divergence times given $Y$ clade pairs. 602 Estimates in (A) and (C) are based on data from all seven species clade pairs, whereas 603 estimates in panels (B) and (D) are based on a dataset in which Lepetodrilus elevatus was 604 excluded. These estimates use the same uniform prior for $\theta_{\mathrm{A}}$ bounded by 0.5 and 5.0 and are 605 based on 500,000 simulated draws from the joint hyperprior and 1,000 draws from the joint 606 posterior using MsBayes Approximate Bayesian Computational software (Hickerson et al. 607 2006b). In panels (C) and (D), the dotted line is the prior for $\Psi$ and the solid line is the 608 posterior for $\Psi$. 
609 Fig. 4 Graph of theta parameter (where $\theta=2 N_{e} \mu, N_{e}=$ effective population size and $\mu=$ the

610 mutation rate) over number of generations based on Metropolis-Hastings Monte Carlo

611 coalescent analysis using Fluctuate version 1.4. Pattern of growth are based on estimates of $g$

612 (the exponential growth rate of the population) generated jointly with $\theta$.

613 Bt, B. thermophilus; Ap, A. pompejana; Hb, H. bergi; Bs, B. symmytilida; Ev, E. vitrea; Lo, L.

614 ovalis; Le, L. elevatus

615 
616

617

618

619

620

621

622

623

624

625

626

627

628

629

630

631

632

633

634

635

636

637

638

639

640

641

642

643

644

645

646

647

648

649

650

651

652

653

654

655

656

657

658

659

660

661

662

663

664

665

\section{References}

Akey JM, Eberle MA, Rieder MJ, et al. (2004) Population history and natural selection shape patterns of genetic variation in 132 genes. Plos Biology 2, 1591-1599.

Arellano SM, Young CM (2009) Spawning, development and the duration of larval life in a deep-sea cold-seep mussel. Biological Bulletin 216, 149-162.

Avise JC (1998) The history and purview of phylogeography: a personal reflexion. Molecular Ecology 7, 371-379.

Bachraty C, Legendre P, Desbruyères D (2009) Biogeographic relationships among deep-sea hydrothermal vent faunas at global scale. Deep Sea Research Part I: Oceanographic Research Papers doi:10.1016/j.dsr.2009.01.009.

Bandelt HJ, Forster P, Rohl A (1999) Median-joining networks for inferring intraspecific phylogenies. Molecular Biology and Evolution 16, 37-48.

Bazin E, Glemin S, Galtier N (2006) Population size does not influence mitochondrial genetic diversity in animals. Science 312, 570-572.

Beerli P, Felsenstein J (1999) Maximum-likelihood estimation of migration rates and effective population numbers in two populations using a coalescent approach. Genetics 152, 763-773.

Beerli P, Felsenstein J (2001) Maximum likelihood estimation of a migration matrix and effective population sizes in $\mathrm{n}$ subpopulations by using a coalescent approach. Proceedings of the National Academy of Sciences of the United States of America $\mathbf{9 8 ,}$ 4563-4568.

Bermingham E, Avise JC (1986) Molecular Zoogeography of Fresh-Water Fishes in the Southeastern United-States. Genetics 113, 939-965.

Chevaldonné P, Jollivet D, Desbruyeres D, Lutz RA, Vrijenhoek RC (2002) Sister-species of eastern Pacific hydrothermal vent worms (Ampharetidae, Alvinellidae, Vestimentifera) provide new mitochondrial COI clock calibration. Cahiers De Biologie Marine 43, 367-370.

Chevaldonné P, Jollivet D, Vangriesheim A, Desbruyeres D (1997) Hydrothermal-vent alvinellid polychaete dispersal in the eastern Pacific. 1. Influence of vent site distribution, bottom currents, and biological patterns. Limnology and Oceanography 42, 67-80.

Cowen JP, Fornari DJ, Shank TM, et al. (2007) Volcanic Eruptions at East Pacific Rise near 9०50'N. EOS, Transactions of the American Geophysical Union 88, 81-83.

Doyle JJ, Dickson E (1987) Preservation of plant samples for DNA restriction endonuclease analysis. Taxon 36, 715-722.

Drummond AJ, Rambaut A (2007) BEAST: Bayesian evolutionary analysis by sampling trees. BMC Evolutionary Biology 7 doi:10.1186/1471-2148-7-214.

Eakins B, Lonsdale P (2003) Structural patterns and tectonic history of the Bauer microplate, Eastern Tropical Pacific. Marine Geophysical Researches 24, 171-205.

Emerson BC, Paradis E, Thebaud C (2001) Revealing the demographic histories of species using DNA sequences. Trends in Ecology \& Evolution 16, 707-716.

Faure B, Chevaldonné P, Pradillon F, Thiébaut E, Jollivet D (2007) Spatial and temporal dynamics of reproduction and settlement in the Pompeii worm Alvinella pompejana (Polychaeta: Alvinellidae). Marine Ecology Progress Series 348, 197-211.

Faure B, Jollivet D, Tanguy A, Bonhomme F, Bierne N (accepted) Speciation in the deep-sea: multilocus analysis of divergence and gene flow between two hybridizing species of hydrothermal vent mussels. PlosOne.

Folmer O, Black M, Hoeh W, Lutz R, Vrijenhoek R (1994) DNA primers for amplification of mitochondrial cytochrome c oxidase subunit I from diverse metazoan invertebrates. Molecular Marine Biology and Biotechnology 3, 294-299. 
Francheteau J, Armijo R, Cheminee JL, et al. (1990) 1 Ma East Pacific Rise Oceanic-Crust and Uppermost Mantle Exposed by Rifting in Hess Deep (Equatorial Pacific-Ocean). Earth and Planetary Science Letters 101, 281-295.

Fretter V (1988) New archaeogastropod limpets from hydrothermal vents; superfamily Lepetodrilacea. II. Anatomy. Philosophical Transactions of the Royal Society of London Series B 318, 33-82.

Glinka S, Ometto L, Mousset S, Stephan W, De Lorenzo D (2003) Demography and natural selection have shaped genetic variation in Drosophila melanogaster: A multi-locus approach. Genetics 165, 1269-1278.

Goldstien SJ, Schiel DR, Gemmell NJ (2006) Comparative phylogeography of coastal limpets across a marine disjunction in New Zealand. Molecular Ecology 15, 3259-3268.

Hall TA (1999) BioEdit: a user-friendly biological sequence alignment editor and analysis program for Windows 95/98/NT. Nucleic Acids Symposium Series 41, 95-98.

Harpending HC, Batzer MA, Gurven M, et al. (1998) Genetic traces of ancient demography. Proceedings of the National Academy of Sciences of the United States of America $\mathbf{9 5}$, 1961-1967.

Haymon RM, Fornari DJ, Edwards MH, et al. (1991) Hydrothermal Vent Distribution Along the East Pacific Rise Crest (9-Degrees-09'-54'n) and Its Relationship to Magmatic and Tectonic Processes on Fast-Spreading Midocean Ridges. Earth and Planetary Science Letters 104, 513-534.

Haymon RM, Fornari DJ, Vondamm KL, et al. (1993) Volcanic-Eruption of the Midocean Ridge Along the East Pacific Rise Crest at 9-Degrees-45-52'n - Direct Submersible Observations of Sea-Floor Phenomena Associated with an Eruption Event in April, 1991. Earth and Planetary Science Letters 119, 85-101.

Hey J, Nielsen R (2004) Multilocus methods for estimating population sizes, migration rates and divergence time, with applications to the divergence of Drosophila pseudoobscura and D. persimilis. Genetics 167, 747-760.

Hickerson MJ, Dolman G, Moritz C (2006a) Comparative phylogeographic summary statistics for testing simultaneous vicariance. Molecular Ecology 15, 209-223.

Hickerson MJ, Stahl EA, Lessios HA (2006b) Test for simultaneous divergence using approximate Bayesian computation. Evolution 60, 2435-2453.

Hudson RR, Slatkin M, Maddison WP (1992) Estimation of Levels of Gene Flow from DNASequence Data. Genetics 132, 583-589.

Hurtado L, Lutz R, Vrijenhoek R (2004) Distinct patterns of genetic differentiation among annelids of eastern Pacific hydrothermal vents. Molecular Ecology 13, 2603-2615.

Johnson SB, Young CR, Jones WJ, Waren A, Vrijenhoek RC (2006) Migration, isolation, and speciation of hydrothermal vent limpets (Gastropoda; Lepetodrilidae) across the Blanco transform fault Biological Bulletin 210, 140-157.

Jollivet D (1996) Specific and genetic diversity at deep-sea hydrothermal vents: An overview. Biodiversity and Conservation 5, 1619-1653.

Jollivet D, Chevaldonne P, Planque B (1999) Hydrothermal-vent alvinellid polychaete dispersal in the eastern Pacific. 2. A metapopulation model based on habitat shifts. Evolution 53, 1128-1142.

Jollivet D, Empis A, Baker MC, et al. (2000) Reproductive biology, sexual dimorphism, and population structure of the deep sea hydrothermal vent scale-worm, Branchipolynoe seepensis (Polychaeta: Polynoidae). Journal of Marine Biological Association of the United Kingdom 80, 55-68.

Jolly MT, Viard F, Gentil F, Thiebaut E, Jollivet D (2006) Comparative phylogeography of two coastal polychaete tubeworms in the Northeast Atlantic supports shared history and vicariant events. Molecular Ecology 15, 1841-1855. 
Jukes TH, Cantor CR (1969) Evolution of protein molecules. In: Mammalian Protein Metabolism (ed. Munro HN), pp 21-123. Academic Press, New York.

Knowlton N, Weigt LA (1998) New dates and new rates for divergence across the Isthmus of Panama. Proceedings of the Royal Society of London Series B-Biological Sciences 265, 2257-2263.

Kuhner MK, Yamato J, Felsenstein J (1998) Maximum likelihood estimation of population growth rates based on the coalescent. Genetics 149, 429-434.

Kumar S, Balczarek KA, Lai Z-C (1996) Evolution of the hedgehog gene family. Genetics 142, 965-972.

Kureth CL, Rea DK (1981) Large-Scale Oblique Features in an Active Transform-Fault, the Wilkes Fracture-Zone near 9-Degrees-S on the East Pacific Rise. Marine Geophysical Researches 5, 119-137.

Le Pennec M, Hily A, Lucas A (1984) Structures gonadiques particulières d'un Mytilidae profound des sources hydrothermales du Pacifique oriental. Comptes Rendus de l'Académie des Sciences de Paris, Série III 299, 725-730.

Lessa EP, Cook JA, Patton JL (2003) Genetic footprints of demographic expansion in North America, but not Amazonia, during the Late Quaternary Proceedings of the National Academy of Sciences of the United States of America 100, 10331-10334.

Mammerickx J, Herron E, Dorman L (1980) Evidence for two fossil spreading ridges in the southeast Pacific. Geological Society of America Bulletin 91, 263-271.

Mammerickx J, Klitgord KD (1982) Northern East Pacific Rise - Evolution from 25 My Bp to the Present. Journal of Geophysical Research 87, 6751-6759.

Matabos M, Thiebaut E, Le Guen D, et al. (2008) Geographic clines and stepping-stone patterns detected along the EPR in the vetigastropod Lepetodrilus elevatus reflects species crypticism. Marine Biology 153, 545-563.

Mullineaux LS, Mills SW, Sweetman AK, Beaudreau AH, Metaxas A, Hunt HL (2005) Vertical, lateral and temporal structure in larval distributions at hydrothermal vents. Marine Ecology Progress Series 293, 1-16.

Mullineaux LS, Wiebe PH, Baker ET (1995) Larvae of Benthic Invertebrates in Hydrothermal Vent Plumes over Juan-De-Fuca Ridge. Marine Biology 122, 585-596.

Naar DF, Hey RN (1989) Speed Limit for Oceanic Transform Faults. Geology 17, 420-422.

O'Mullan GD, Maas PAY, Lutz RA, Vrijenhoek RC (2001) A hybrid zone between hydrothermal vent mussels (Bivalvia : Mytilidae) from the Mid-Atlantic Ridge. Molecular Ecology 10, 2819-2831.

Plouviez S, Daguin C, Hourdez S, Jollivet D (2008) Juvenile and adult scale-worms, Branchipolynoe seepensis, in Lucky Strike hydrothermal vent mussels are genetically unrelated. Aquatic Biology 3, 79-87.

Posada D, Crandall KA (2001) Intraspecific gene genealogies: trees grafting into networks. Trends in Ecology \& Evolution 16, 37-45.

Rogers AR, Harpending H (1992) Population-Growth Makes Waves in the Distribution of Pairwise Genetic-Differences. Molecular Biology and Evolution 9, 552-569.

Rozas J, Sanchez-DelBarrio JC, Messeguer X, Rozas R (2003) DnaSP, DNA polymorphism analyses by the coalescent and other methods. Bioinformatics 19, 2496-2497.

Sadosky F, Thiebaut E, Jollivet D, Shillito B (2002) Recruitment and population structure of the vetigastropod Lepetodrilus elevatus at 13 degrees $\mathrm{N}$ hydrothermal vent sites on East Pacific Rise. Cahiers de Biologie Marine 43, 399-402.

Shank TM, Fornari DJ, Von Damm KL et al. (1998) Temporal and spatial patterns of biological community development at nascent deep-sea hydrothermal vents $\left(9^{\circ} 50^{\prime} \mathrm{N}\right.$, East Pacific Rise). Deep Sea Research Part II: Topical Studies in Oceanography 45, 465-515. 
Skibinski DOF, Gallagher C, Beynon CM (1994) Mitochondrial-DNA Inheritance. Nature 368, 817-818.

Smith CI, Farrell BD (2005) Range expansions in the flightless longhorn cactus beetles, Moneilema gigas and Moneilema armatum, in response to Pleistocene climate changes. Molecular Ecology 14, 1025-1044.

Sunnucks P (2000) Efficient genetic markers for population biology. Trends in Ecology \& Evolution 15, 199-203.

Tajima F (1989) Statistical-Method for Testing the Neutral Mutation Hypothesis by DNA Polymorphism. Genetics 123, 585-595.

Tunnicliffe V (1991) The biology of hydrothermal vents: ecology and evolution. Oceanography and Marine Biology. An annual review 29, 319-407.

Tunnicliffe V, Embley RW, Holden JF, et al. (1997) Biological colonization of new hydrothermal vents following an eruption on Juan de Fuca Ridge. Deep-Sea Research Part I-Oceanographic Research Papers 44, 1627-\&.

Tyler PA, Pendlebury S, Mills SW, et al. (2008) Reproduction of gastropods from vents on the East Pacific Rise and the Mid-Atlantic Ridge. Journal of Shellfish Research 27, 107-118.

Van Dover CL, German CR, Speer KG, Parson LM, Vrijenhoek RC (2002) Evolution and biogeography of deep-sea vent and seep invertebrates. Science 295, 1253-1257.

Van Dover CL, Trask JL, Gross J, Knowlton A (1999) Reproductive biology of free-living and commensal polynoid polychaetes at the Lucky Strike hydrothermal vent field (Mid-Atlantic Ridge). Marine Ecology-Progress Series 181, 201-214.

Young CR, Fujio S, Vrijenhoek RC (2008) Directional dispersal between mid-ocean ridges: deep-ocean circulation and gene flow in Ridgeia piscesae. Molecular Ecology 17, 1718-1731. 


\section{Author information box}

792 This study is a component of S. Plouviez's Ph.D. project, which investigates comparative 793 phylogeography of deep-sea hydrothermal vent species. Her research uses multiple species 794 and markers to examine demographic processes and species dispersion along the East Pacific 795 Rise. The Ph.D. is co-supervised by D. Jollivet and F.H. Lallier. T.M. Shank, B. Faure, C. 796 Daguin and F. Viard made significant contributions to this study through the design of 797 sampling strategies, field collections, and editing that improved the manuscript, initially 798 written by the first author. 

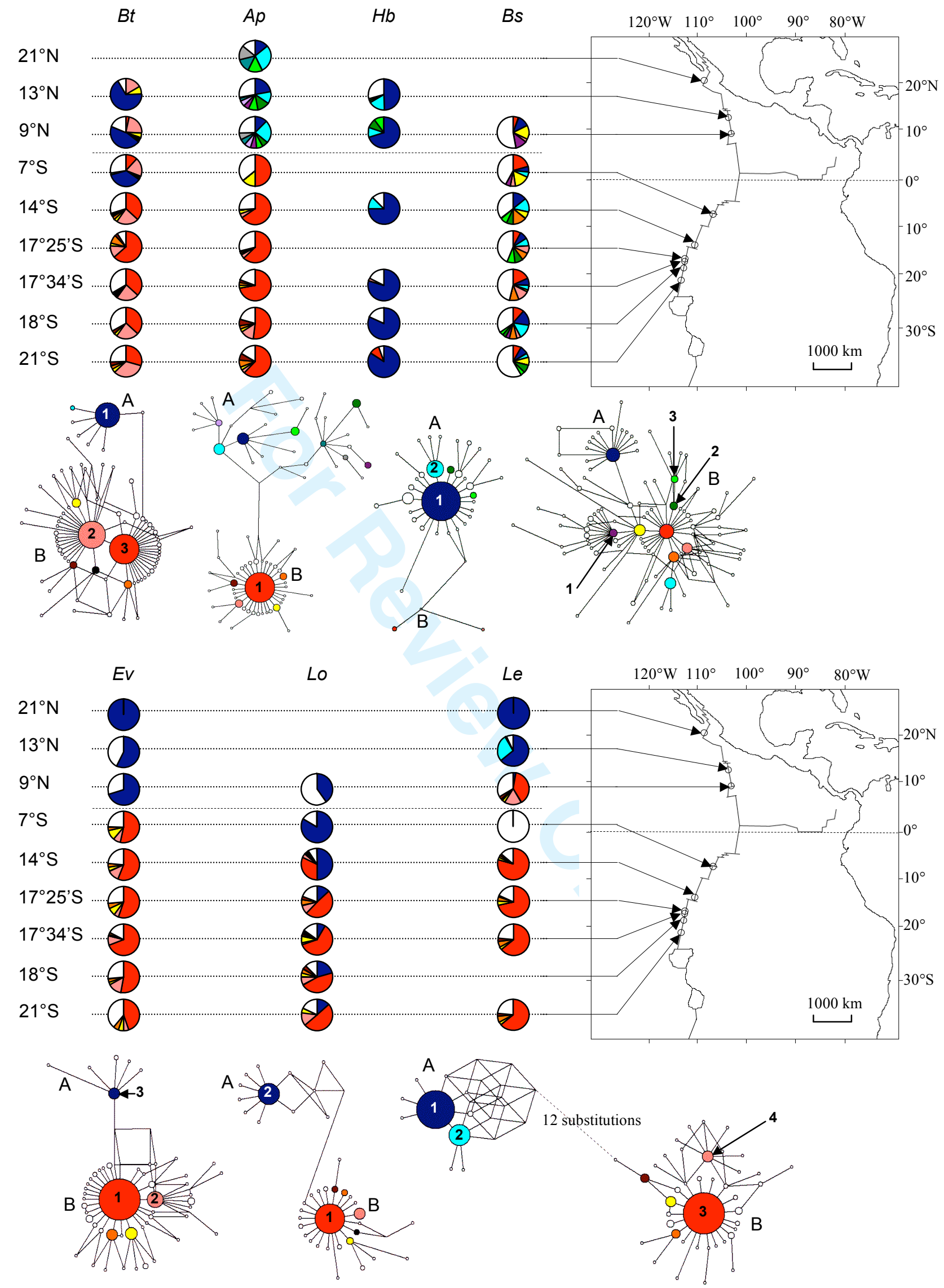


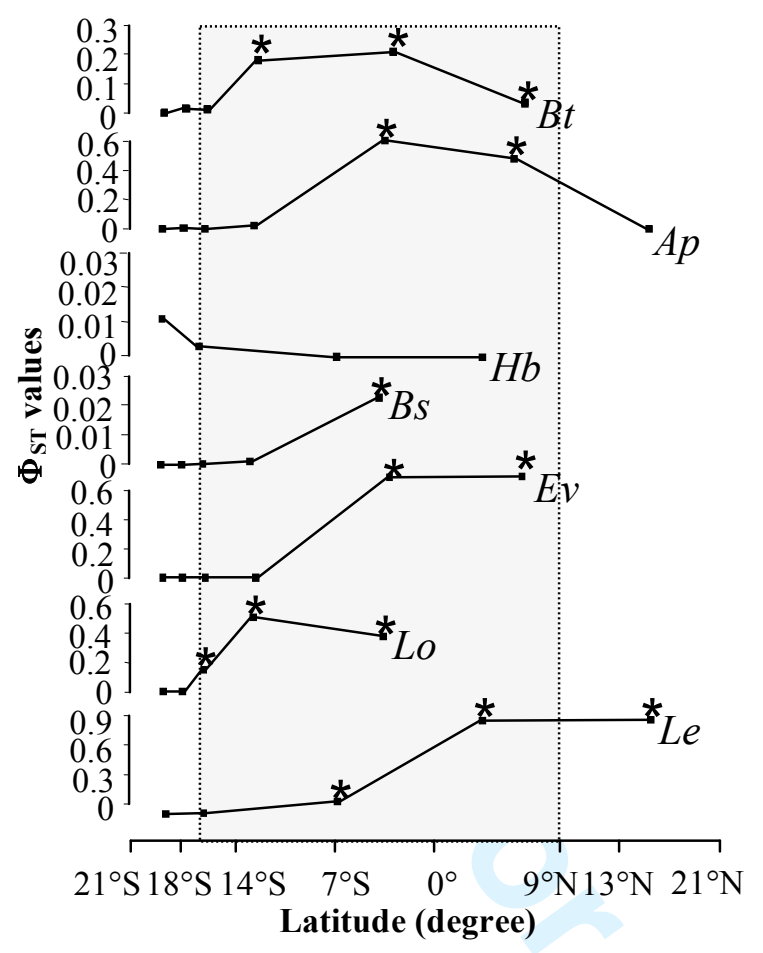


Joint Posterior Density of $\Omega$ and $E(\tau)$
A $\quad \mathrm{Y}=7$ clade pairs
B $\mathrm{Y}=6$ clade pairs
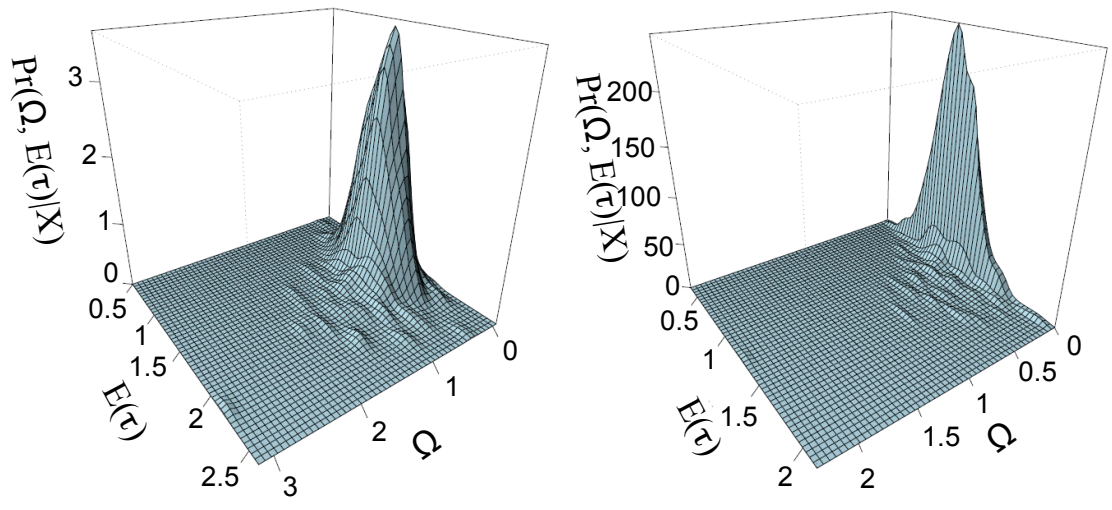

Posterior Density of $\Psi$

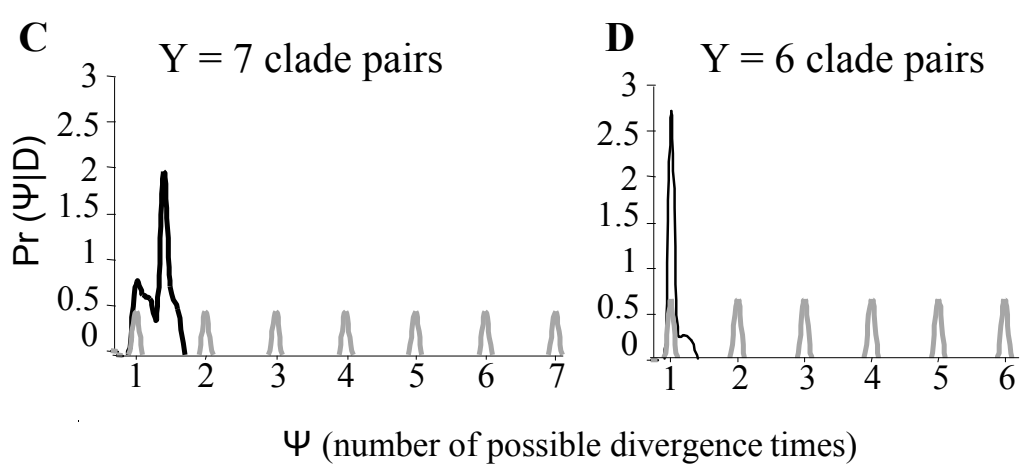




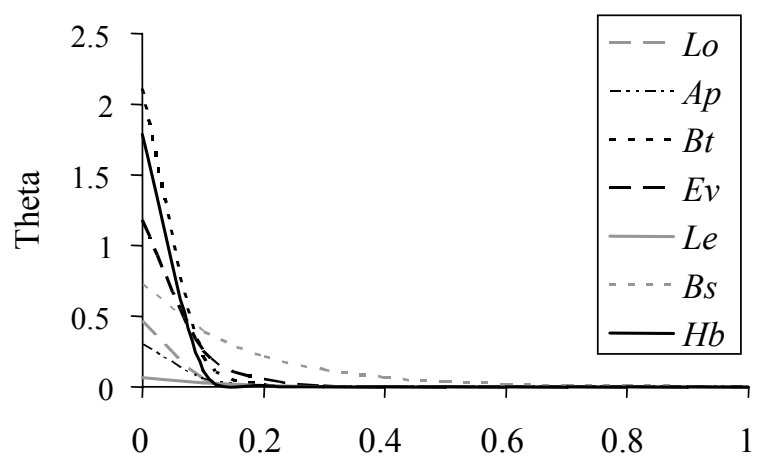

Millions of generations before now 